\title{
'I consider myself to be a service provider': Discursive identity construction of the forensic linguistic expert
}

\section{Introduction}

Despite the many developments in forensic linguistics over the last few decades, leading to its now well-established status as an academic discipline, the applied dimension of the field as directly contributory to justice delivery is yet to receive the scholarly attention it deserves. In particular, little is known about the professional identity of those forensic linguists who provide investigative and/or evidential assistance in legal contexts. The literature, in the form of both academic publications and popular-science treatments of the field only provides anecdotal evidence as to what this identity actually entails; practice-based suggestions are often made in passing and case studies tend to be limited to reporting on the methodology and findings (e.g. Coulthard 1997; Grant 2013, 2017; Shuy 2008).

Reflecting on the progress the International Association of Forensic Linguists (IAFL) had made in the fifteen years since posting its aims and objectives on its website, Ronald Butters, the organisation's then-president argued in 2012 that IAFL 'still [had] work to do' in two of the nine announced goals. The first of those, 'drawing up a Code of Practice' was achieved a few years ago (IAFL 2013), but the second, 'research into the practice, improvement, and ethics of expert testimony and the presentation of linguistic evidence' (Butters 2012: 352) has still not been pursued in any systematic fashion.

Similarly slow in keeping up with the field's organic growth has been the law. In the United Kingdom (but also in many other jurisdictions) forensic linguistics is not formally recognised as a profession, nor is it statutorily regulated, meaning that pretty much anyone claiming expertise can act as an expert witness in cases where language-related evidence is involved ${ }^{1}$. Possibly the closest forensic linguistic experts in the UK came to being regulated was in 2008, when, following a consultation process in the forensic linguistic and forensic speech science communities, the Council for the Registration of Forensic Practitioners produced a set of accreditation criteria. Unfortunately, due to funding cuts, the Council was disbanded and the system was never implemented. More recently, however, the idea of a statutory recognition and/or regulation of forensic linguistics returned in the shape of two notable developments in the UK Parliament. In September 2015, the Parliamentary Office of Science and Technology (POST) published a briefing note on forensic linguistics (Bunn and Foxen 2015). The office is the UK Parliament's in-house science communication unit helping Members of Parliament and Peers to make informed legislation-related decisions. In April 2016, in turn, it was posited in the House of Commons that the Parliament should work towards a bill that would "place a duty on the forensic science regulator to establish a code of practice and conduct for the providers and practitioners of forensic linguistics in the criminal justice system' (Hansard 2016, vol. 608, col. 934).

It is against this background that this article offers an empirically-based examination of just what it means to be a forensic linguistic expert witness. More specifically, it applies a corpusassisted discourse analysis to eleven interviews with practising expert linguists, to find out how they construct their own professional identity. Our focus is thus on forensic linguistics narrowly defined as the provision of expert input in forensic and judicial contexts in relation to what Gibbons (2011) calls 'communication evidence'. In undertaking this study, we hope not only to uncover and make sense of the constitutive elements of the discourse in question, but to set an agenda for future systematic studies as well. 


\section{Research background}

To the best of our knowledge, this is the first data-driven study to examine the professional identity of the forensic linguist as expert witness and, to better inform our analysis of the data, we feel it necessary to briefly explore the conceptual space occupied by identity and professional identity research. In this section we also demonstrate how scholars have approached the task of examining professional identity in other fields. Finally, we connect research on forensic linguist experts and their practice to existing research on professional identity.

\subsection{Identity and professional identity}

Identity is a highly debated and ideologically loaded concept which can be approached from an essentialist or a constructionist perspective (Brubaker and Cooper 2000). It was traditionally viewed as a static, passive and singular entity, which pre-exists in the individual (Tracy 2011), but more recently the social-constructionist perspective has gained currency. It conceptualises identity in the plural and sees identities as multifaceted and dynamic constructs that emerge in social interaction (Marra and Angouri 2011, Tracy 2011). Accordingly, identity is no longer viewed as something that people are, but rather something that they do and perform (Marra and Angouri 2011). Our underlying epistemological position in this article is that because identity performance is made possible predominantly by language use, both in the actual professional context and outside of it, language can be used as a suitable research site.

Drawing on a multitude of authors and theories from various fields, Bucholtz and Hall (2005) offer a constructionist framework for the analysis of identity that is centred around five principles: emergence, positionality, indexicality, relationality and partialness, with the first four bearing direct relevance to the present study. The emergence principle assumes that identities do not precede discourse, but are an emergent product of the interaction. According to the positionality principle, identities are not one-dimensional and individuals can assume multiple positions. The indexicality principle suggests that there are several linguistic structures and forms which occur at all levels of language, and function to index or construct identities. In particular,

'[i]dentity relations emerge in interaction through several related indexical processes, including: (a) overt mention of identity categories and labels; (b) implicatures and presuppositions regarding one's own or others' identity position; (c) displayed evaluative and epistemic orientations to ongoing talk, as well as interactional footings and participant roles; and (d) the use of linguistic structures and systems that are ideologically associated with specific personas and groups.' (Bucholtz and Hall 2005: 594)

The relationality principle assumes that the relationship to other social actors plays a fundamental role in the construction of identities. It is through these other social actors and the relationships to them, that identities gain social meaning.

Some scholars consider professional identity to be identity work that is performed inside the workplace context, while others have situated it outside of the workplace. For example, Ibarra (1999) defines professional identity as one's professional self-concept which is based on attributes, beliefs, values, motives and experiences. However, according to Wadeson (1977) and Feen-Calligan (2005), professional identity consists of not only an individual's professional self-concept within the professional role, but also the profession's collective identity. One way in which a profession's collective identity is constructed is through official documents, such as codes of practice and ethics (Bouchard 1998), and mission statements 
(Koller 2011). Additionally, collective identities in an institution or workplace can be constructed and co-constructed through a shared repertoire of resources, such as specific vocabulary and routines (Angouri and Marra 2011). When people share the same knowledge or take part in the same activities, they develop a shared identity (Lave and Wenger 1991).

When it comes to the adjective 'professional', Boswood (1999) and Sullivan (2000) suggest that it carries particular expectations, such as high standards of competence, including superior knowledge and skills, and high standards of moral responsibility. In a recent study, Li and Ran (2016) develop this understanding of 'professional' to define professional identity. Adopting the social-constructionist view of Bucholtz and Hall (2005), and using Spencer-Oatey's (2007) definition of identity, they take professional identity to mean 'one's professional self-image, consisting of such attributes as professional role, professional competence and professional ethics' (Li and Ran 2016: 48).

$\mathrm{Li}$ and Ran (2016) demonstrate that professional identity will always be cognitive and social in nature regardless of whether it is construed individually, relationally or collectively. This means that people will form cognitive representations of their professional identity and negotiate and construct it in social interaction. While Bucholtz and Hall (2005) stress that identity construction is relational, Li and Ran (2016) find in their study that professional identity construction is also an interrelational phenomenon and that self-professional identities are constructed through other-professional identities, specifically the deconstruction of otheridentities. They describe van Dijk's (2000) classic discursive representation of 'us vs. them' to show that the self-professional identity is positively presented and constructed through the negative presentation and deconstruction of 'them'. They develop this discursive representation of 'us vs. them' and categorise the constructions vs. deconstructions into three dyads, which represent elements of the professional identity: (1) expert vs. nonexpert identity; (2) insider vs. outsider identity; and (3) authentic vs. artificial identity (Li and Ran 2016: 50).

In addition to building on Bucholtz and Hall's (2005) relationality principle, Li and Ran (2016) expand the emergence principle and suggest that certain attributes of self- and otheridentities can be more or less salient at different points in the same interaction. Overall, Li and Ran (2016: 47) define professional identity construction as:

'the dynamic and interrelational act of enacting, presenting, negotiating, challenging or verifying one's own and others' attributes of professional role, competence and ethics in a specific sociocultural discourse context.'

\subsection{Previous studies on professional identity construction}

The construction of professional identities has been examined for a variety of occupational groups. Heffer (2005) shows how an important identity that Crown Court judges construct for themselves is that of helpers to the jury, and Tracy (2009) demonstrates how, during a samesex marriage case, the distinctive identities of six appellate judges were created through questioning style, frequency and length of questions, format, and content focus. Two more studies from the courtroom setting are Chaemsaithong (2011 and 2012), where the focus is on medical expert witnesses and their construction of expertise during examination. A number of other studies have investigated the transition from student to professional identity, where the occupational groups of interest have been lawyers (Mertz 2007), doctors (Pratt et al. 2006), teachers (Dvir and Avissar 2013) and social workers (Wiles 2013).

Most of these studies emphasise the emergent nature of professional identity within the institutional context, and therefore examine professional identity construction through the performance of work practice. However, only a few studies have looked at the construction of professional identity outside the workplace context by exploring how practitioners actually conceptualise their practice when they are not at work, or 'off duty'. One example is Watson 
(2006), who interviewed an experienced teacher and analysed his narratives of practice. When professionals talk about their professional practice they are constructing their professional identity because when an individual recounts events and tells stories, they impose their own subjective interpretation of events by choosing from an array of linguistic and grammatical structures to make their experience meaningful (Dyer and Keller-Cohen 2000, Polkinghorne 1988). What Watson (2006) found was that the teacher drew on a number of resources to construct his professional identity, including professional knowledge, personal experience, the 'micro-politics' of the setting, and the wider socio-cultural contexts. Another example of a study which examined professional identity outside of the workplace context was Verling (2014). Because of the limited amount of literature on the professional identity of counselling psychologists, she adopted a mixed-methods approach, including the use of qualitative interviews, to examine both the collective and individual professional identities of counselling psychologists. This combination of quantitative and qualitative data collection and/or analysis is an emerging trend in much of the identity literature reviewed, especially when there was little or no existing research on the particular identities examined (e.g. Heffer 2005, Zhang and Mihelj 2012).

However, a study which did not use quantitative tools, but was based on interview data, was Wiles (2013). It adopted a social psychological approach to discourse analysis and manually examined recurrent words, phrases and patterns in the interview transcripts to identify interpretative repertoires of emerging social workers. Wiles (2013) found that professional identity was constructed through the following resources: (1) one's desired traits, i.e. an ideal identity; (2) the collective identity of the profession; and (3) the process in which an individual begins to perceive themselves as a professional.

There are no studies devoted to examining specifically the professional identity of the forensic linguist and, as indicated in the introduction, what we do know is based on reports by forensic linguists writing about their own experience of providing expert evidence (e.g. Coulthard 1997, 1998, 2005; Coulthard and Johnson 2007; Coulthard et al. 2010; Durant 1996; Grant 2013 and 2017; Olsson 2008; Shuy 1993, 2000, 2002, 2006, 2008 and 2010). Among the topics one can find in the reports are the choice of method (e.g. Olsson 2012), limitations of the data (Coulthard et al. 2010; Grant 2013 and 2017), working relationship with the instructing lawyers (Shuy 2002, 2006) and ethical issues (Butters 2009, Shuy 2009). Interestingly, aspects of the identity are often discussed through orientation to another group (similar to Li and Ran 2016): other forensic linguists, non-expert witnesses or lawyers/advocates. We outline these dyads briefly below.

\subsubsection{Insider vs. outsider forensic linguists}

According to Shuy (2000), there are two types of forensic linguist: insiders and outsiders. Insiders are involved in law cases, often producing reports and testimonies, and occasionally testifying in court as expert witnesses. Outsiders are not involved in litigation, but instead study the language of the law, including statutes, trial language, police interviews and witness language. Fundamentally, insider forensic linguists are constrained, controlled and restricted because of the context where they work (Shuy 2000).

\subsubsection{Non-expert vs. expert witnesses}

There are two categories of witnesses in courts: witnesses who are personally involved in the case and expert witnesses, who have expertise beyond that of the court in a specialist field and aim to assist the court by providing opinions from the analysis of evidence (Coulthard 2010, Shuy 2009). Unlike ordinary witnesses, the opinion of an expert can only be called on if it is grounded in research and investigation, and is perceived to help the court in reaching a decision (Johnson and Coulthard 2010). Expert witnesses are required to produce a report and if the case 
goes to trial they must testify, like ordinary witnesses, under oath. However, the testimonies of witnesses and expert witnesses are received in different ways (Lagorgette 2011). This is because the testimony of a witness is personal and subjective, whilst that of the expert witness is presumed to be impartial and objective, and gains authority through the status of expertise (Lagorgette 2011).

\subsubsection{Advocates vs. educators}

Unlike lawyers, who owe a duty of loyalty to their clients, '[t]he expert's only duty of loyalty is to her science' (Ainsworth 2010: 281). In order to be independent, the expert will not be affiliated with the hiring party's goals nor withhold information that transgresses from their legal position (Lubet 1998-1999). In order to be objective, the expert must not be concerned with the consequences for the client and they must dispassionately read the facts and data (Lubet 1998-1999). Therefore, there is an expectation from the law that expert witnesses should be unbiased educators rather than advocates of their own moral ethics or their hiring party's values (Sacks 1990). Butters (2009) also raised the issue of remuneration for expert witness work, in particular the practice of those linguists who make a living out of expert witness work and those who provide investigative assistance pro bono. While the law expects impartiality, in reality, experts in adversarial systems are purposely and strategically selected by lawyers (Sack 1990), and are largely influenced by their hiring parties (Ainsworth 2010), and sometimes their own moral ethics (Butters 2009). For example, Finegan (2009), a linguist, talks about how he is often approached with a request to assist one party in a proceeding, rather than the court.

\section{Data and method}

As mentioned above, our research question is addressed through discourse analysis, with 'discourse' understood as 'a system of statements which constructs an object' (Parker 2015: 151). The statements, or texts, that bring professions into being and maintain them can be many and varied. Long-established professions, whose social presence is often enshrined in legal instruments, can well be studied from essentialist perspectives but at least since Foucault (1972) even in such cases it has been arguably more revealing to adopt constructionist approaches. It certainly makes sense to do so for less established or emerging professions, where the discourse, being reflective of the social reality, is at the same time still ontologically constitutive of it. In the case of the forensic linguistic expert, or in Shuy's words (2000: 68) 'insider forensic linguist' (hereafter referred to as 'practitioner'), the kinds of texts one could explore are for example media representations of the involvement of forensic linguists in criminal cases, the (limited) references to communication evidence in case law, forensic linguistics course brochures, the Constitution of the International Association of Forensic Linguists etc. In this article we look into what, given our epistemological perspective, is perhaps an obvious point of departure: the discourse of the practitioners themselves representing their professional experience.

The participants of the study were eleven forensic linguistic experts (five female and six male), defined as individuals with specialised knowledge and at least five years' experience of providing investigative and/or evidential assistance in legal contexts. Experience of crossexamination was not a requirement. They were selected using a convenience sampling method and to represent various parts of the world and different legal systems; they are based in Australia, Germany, Spain, the United Kingdom, and the United States. An additional criterion was that the practitioners should represent the various specialisations of forensic linguistics, such as authorship attribution and profiling, trademark disputes, meaning disputes etc. Furthermore, the majority of the participants are academics who do casework alongside their 
university work, with three of the eleven interviewees perceiving themselves as full-time forensic linguists. This may not reflect the overall population pattern within the field, as very few people can make a living by consulting as expert linguists on a full-time basis.

Semi-structured qualitative interviews lasting between thirty and forty-five minutes were carried out with each participant. ${ }^{2}$ All but two interviews were conducted via Skype, with one being conducted face-to-face and one over the telephone. All participants were asked the same open-ended questions based on Verling's (2014) work and Rieber and Stewart's (1990) edited volume on linguists as expert witnesses (see Appendix II). Follow-up exploratory questions were also asked, building on the participants' replies to the 'generic' questions. While they all covered several important areas, there are of course many more questions that could have been asked. The interviews were audio-recorded and then transcribed verbatim. A few participants indicated they did not want some of what they said on record and so it was not transcribed. To ensure anonymity the names of the participants were replaced with $\mathrm{P}(1,2 \ldots 11)$ in the transcripts. Other potentially identifying information (e.g. academic affiliation, case references etc.) was removed as well. The corpus contains 53,100 words.

As indicated earlier, the recent literature on identity and professional identity construction has taken a mixed-methods approach by combining qualitative and quantitative data analysis. This study follows suit; ours is essentially a corpus-assisted discourse study (CADS) supplemented with thematic analysis. A CADS approach involves the compilation of specialised corpora and aims to uncover 'non-obvious meaning' in the discourse type (Partington et al. 2013: 11). It brings together the quantitative techniques of corpus linguistics, and the qualitative tools of discourse analysis in a "methodological synergy" (Baker et al. 2008: 287). Initially, CADS derived as a result of the criticism of Critical Discourse Analysis, which tends to be qualitative in nature, and therefore the results may not be generalisable (Orpin 2014). On the other hand, corpus linguistics has been criticised for its tendency to highlight stereotypical generalisations and to neglect the context (Baker 2006). This is ultimately avoided through the discourse analytical phase of the CADS approach, which is predominantly concerned with the context (and co-text by definition).

With CADS being a combination of corpus linguistics and discourse analysis, it is possible to adopt one of two macro starting points (Taylor 2013). The researcher can either draw on the tools of corpus linguistics to look at the data to identify areas which require further examination (e.g. Partington 2006, Jaworska 2016), or they can begin with discourse analysis and select a discourse-analytical frame (e.g. Tkačuková 2015, Schröter and Storjohann 2015). This distinction corresponds to that proposed by Tognini-Bonelli (2001), between corpus-driven and corpus-based approaches, respectively.

This study combines the two approaches. It is corpus-based in that the analytical focus is on expressions of stance, understood after Biber et al. (1999: 966) as the participants' 'personal feelings, attitudes, value judgments, or assessments' that they display when describing their work to the interviewer. The analysis will look at the ways in which the informants use markers of stance as resources in the construction of their professional identity, in line with the assumptions behind Bucholtz and Hall's (2005) indexicality principle.

At the same time, the corpus-driven dimension of the analysis will use stance markers as a convenient epistemic access point to other potentially revealing parts of the discourse. It will thus look into how the participants talk about their work as well as what they talk about when referring to their professional experience. As mentioned in Section 2, collective identities in an institution or workplace can be constructed and co-constructed through a shared repertoire of resources, such as specific vocabulary and routines (Angouri and Marra 2011), and it is interesting to see just what these could be in this case (albeit strictly speaking outside of a workplace context). It is important to note, however, that we are uncertain about the generalisability of the resulting findings, given the relatively small number of participants. 
Nevertheless, we believe that this problem is outweighed by the potential knowledge gains and ideas for related research.

As regards the methodological procedure, first a word list was produced using the corpus software AntConc (Anthony 2016) and stance-associated lexemes based on Biber (2006) were identified. For reasons of time economy, the search was limited to selected categories only, viz. modal and semi-modal verbs, as well as verbs, adjectives and adverbs of certainty, likelihood and attitude (for the full list see Appendix I). It was assumed these would be numerous enough to warrant an in-depth analysis. The particular lexemes were analysed with the AntConc concordance tool. To make sense of the apparently recurring patterns, a slightly modified version of Braun and Clarke's (2006) thematic analysis was applied: to remain unbiased we skipped the first of their six steps and did not read the interviews through a discourse analytical lens before embarking on the corpus analysis. We chose to let the transcripts return the potentially relevant passages instead and we then applied the other five steps: generating codes, searching for themes, reviewing themes, defining and naming themes, and producing the report. To exemplify the procedure, we briefly present our analysis for one of the stance markers below.

\subsection{Know}

The epistemic stance marker ' $\mathrm{I} /$ we know' is potentially interesting as it could be used explicitly in reference to the participants' professional knowledge. As Morris et al. (2000) argue, professions require a body of knowledge, i.e. the knowledge and competencies of its members (Morris et al. 2000).

A look at the concordances for 'know' revealed that it was used almost 71 percent of the time as part of the discourse marker 'you know'. Despite this, there were still 91 uses of 'know' occurring with the first person singular pronoun as the subject. This construction can be used to encode personal stance and, by extension, could provide insight into the body of knowledge of the profession. Consequently, these uses of 'know' were manually coded with respect to the type of knowledge involved. Similar types of knowledge were collated and then this list was explored in search for patterns, or themes of knowledge. All of the codes, including repeated ones, were then assigned to a theme. Some themes only have a few codes in them and cannot be considered as collectively identity-building. However, there are three major recurring themes of knowledge with at least 13 codes in each (see Table 1). These are knowledge of: (1) one's own and other's practice, abilities and expertise (17 codes); (2) forensic linguistics and the legal process (14 codes); and (3) the background of the case (18 codes). Instances of this final type of knowledge appear predominantly in the negative (all but one of the interviewees who refer to this type of knowledge want limited information about the background of the cases they are working on).

Table 1: Themes of knowledge

\begin{tabular}{|c|c|c|}
\hline Example & Codes & Major Themes \\
\hline $\begin{array}{l}\text { P1: because I know [name] } \\
\text { works with that if they are longer } \\
\text { cases and there is statistical } \\
\text { analysis involved erm I will I } \\
\text { will refer it to somebody else } \\
\text { who I know can do it }\end{array}$ & $\begin{array}{l}\text { Others' expertise, others' } \\
\text { previous work, others, } \\
\text { abilities, different } \\
\text { languages, own abilities, } \\
\text { others in university, others, } \\
\text { opinions, others' actions, } \\
\text { own practice }\end{array}$ & $\begin{array}{l}\text { (1) One's own and others' practice, } \\
\text { abilities and expertise }\end{array}$ \\
\hline
\end{tabular}




\begin{tabular}{|l|l|l|l|}
\hline $\begin{array}{l}\text { P7: I know that they're [cross- } \\
\text { examiners] not asking me me } \\
\text { because they want to know the } \\
\text { answer they are saying it because } \\
\text { they are trying to build a case } \\
\text { against my case and you always } \\
\text { have to remember that }\end{array}$ & $\begin{array}{l}\text { Lawyer tactics, law/legal } \\
\text { terms, legal system, } \\
\text { courtroom discourse, } \\
\text { developments } \\
\text { accreditation, language in } \\
\text { the law, criticisms and } \\
\text { allegations in the field }\end{array}$ & $\begin{array}{l}\text { (2) } \\
\text { process }\end{array}$ \\
\hline $\begin{array}{l}\text { P2: well I try to know as as as } \\
\text { little as possible about the case I } \\
\text { try but sometimes that's not very } \\
\text { easy because they especially the } \\
\text { client they want to tell you I'm } \\
\text { right you know }\end{array}$ & $\begin{array}{l}\text { the background of the case, } \\
\text { the case allegations, } \\
\text { the accusations }\end{array}$ & (3) The background of the case \\
\hline
\end{tabular}

This coding procedure was repeated with each of the stance markers as the point of departure. As anticipated, it was often the case that several stance markers revealed the same code or theme. When a theme was identified, we made sure it appeared in at least six of the eleven interviews before it was considered as representing the intersubjective view of the group. We then reviewed all of the themes, and defined and named them. We do, however, appreciate that with more participants and other questions these themes are subject to change in future research. It is also likely that a number of the codes and themes appeared as a result of the specific questions. However, the latent themes (Braun and Clarke 2006) seem to have arisen spontaneously in that the interviewer did not evoke them explicitly or purposefully.

\section{Findings}

To make sense of the codes identified, we represented them visually in a diagram (Fig. 1). This shows how they are interrelated and proposes a number of overarching themes.

\section{Figure 1: Initial thematic map}

[Figure 1 goes here]

What became clear following this early attempt at a typology, was that the relationships between the codes, and between the codes and the themes were complex and confusing. Following Braun and Clarke (2006), we therefore refined the thematic map by removing or collapsing some of the candidate themes, and subsuming the codes under revised themes (Fig. 2). In the subsequent sections, we present our findings for each of the themes. Where we quote from our informants, we do not use a specialist transcription system to avoid distracting the reader with what would be in effect an unnecessary level of detail. At the same time, we have represented the informants' responses verbatim and only inserted punctuation marks to aid comprehension where absolutely necessary.

\section{Figure 2: Final thematic map}

[Figure 2 goes here]

\subsection{Customary practice and procedures}

This theme refers to how the experts go about doing their job at the most basic, practical level from the moment they are approached by a party in litigation until they present their evidence in court (but it turns out it is only in a small proportion of cases that an expert actually ends up testifying in court). It is about the procedures they employ and the decisions they make. What 
the latter are informed by is presented mostly under the theme of 'Professional and social duty' in 4.2 below.

The picture emerging is one of experts making often difficult methodological decisions on the one hand, and having to explain those decisions and the subsequent findings to lay audiences on the other. The decisions tend not to be straightforward owing to the nature and limited amount of forensic data:

(1) [forensic linguistics is] a very strange field in the sense that (...) with with DNA you know erm the the science is much more measurable erm having a small amount of data is not an impediment to doing an analysis so with I think that forensic linguistic analysis is always going to be highly specialised (Participant 8)

The informants were all asked specifically how they managed the task of communicating scientific knowledge to lay audiences (see Question 10 in Appendix II). A common response was that they drew on their experience as teachers to translate and/or explain complicated linguistic terminology in the report and on the witness stand, and various practical solutions were mentioned:

(2) I make believe I am teaching a class (P7)

(3) actually having erm erm experience in teaching gives you also like the tools to be able to approach a not $[\mathrm{sic}]$ scientific audience and then explain in a way that they can understand (P2)

(4) where you think to yourself well that that's a slightly tricky concept for a layperson to have to to have to take on board so what I do is I will put a glossary in my report (P8)

(5) I try to make my reports in fairly plain English and any technical terms that I'm using like type token ratios or whatever erm I would explain briefly what that meant (P3)

Another specific question was about cross-examination (Question 15 in Appendix II), where for a variety of reasons the science communication task can become doubly difficult. According to Shuy (2002:5), '[f]or those who have never experienced cross-examination, there is no way to emphasise how emotionally draining it can be'. One informant confirms Shuy's (2002) claim:

(6) I've never managed to cope very well with cross-examination I mean emotionally it is very very difficult $(\mathrm{P} 10)$

A few others, however, while implicitly acknowledging the distressing nature of the interaction, take a more relaxed view and additionally show an awareness of the need to prepare themselves for what is going to happen:

(7) it's not that bad it's usually that they're trying to find a hole but I'm usually well aware of what they're trying to do (P11)

(8) I know that they're not asking me because they want to know the answer (...), they are saying it because they are trying to build a case against my case and you always have to remember that $(\mathrm{P} 7)$

(9) the cross-examiner is going to question everything and (...) I suppose what you have to do is stay calm and be sure that what you've done you've done unbiased and you've done objectively (P2) 
Rather than the cross-examiner, however, the one type of actor that dominates the discussions of communication practices before and during the trial is the instructing lawyer. The data suggests that much of the expert linguist's professional practice is about the ability not only to explain methods and findings, but also to understand and respond effectively to the professional legal culture and its communicative practices. It appears that linguistic experts' ability to fulfil their contractual obligations is a function of their familiarity with the institutionally imposed norms and expectations legal contexts carry; at least some knowledge of how the legal system works is indispensable. While this general finding is the result of expressly made comments, it is interesting to see it confirmed also at the meta-level of the terminology the experts use - it can be argued the transcripts abound in legal terms not only because of the topics discussed but also the experts' experience of, and familiarity with, legal contexts.

Another finding is that the experts' customary professional practice, defined by the adversarial nature of the legal process (which is the case also in inquisitorial systems), has led to an awareness that their work is likely to get scrutinized by other linguists, whether courtappointed or working for the opposing party, and challenged by lawyers. This sub-theme is evoked by all of the informants and, with no prompting or priming from the interviewer, six of them use the term 'the other side', for example:

(10) it helps to ask for the briefs of both sides so you can see what the other side is also saying (P9)

(11) the other side are going to kind of try to really rubbish you in any way that they possibly can (P8)

'The other side' thus directly impacts on the experts' work because in terms of audience design (in the sense of Bell 1994) the linguists working for the opposing party are perhaps the most important addressee of expert reports. This kind of relationship is acknowledged explicitly by two of the informants, who at the same time see it as an opportunity to ensure best practice when analyzing data and presenting findings:

(12) in my case the best that I can often do is to try and imagine what I would do were I a linguist on the other side of the case (...) for me that's probably the most single helpful thing that er I do for in analysing a case (P9)

(13) we [P7 and a colleague] then play devil's advocate and try to make believe that we are on the other side and be the expert on the other side and attack it as viciously as we can (P7)

\subsection{Professional and social duty}

Shuy (2009), in his introduction to a special issue of this journal devoted to ethical questions in forensic linguistics, identified a potential professional clash between forensic linguists and lawyers, whereby the 'absolute requirement of scientific objectivity and neutrality can conflict with a very different ethical requirement incumbent upon lawyers: to be an advocate for their clients and to make every effort to win the case for them within the framework of ethical legal practice' (2009: 221) (see also Ainsworth's point quoted in 2.2.3 above). Our informants show unanimity in seeing themselves as objective and independent providers of linguistic expertise whose duty is to assist the court. While remuneration was not raised specifically, some did acknowledge the ethical issues with being paid by the hiring party and doing pro bono work, which could affect impartiality, as discussed by Butters (2009) and Nunberg (2009). Nevertheless, those working in adversarial systems reject the idea of the 'hired gun', i.e. an expert sympathetic to the instructing party's agenda and shaping his/her conclusions accordingly. Becoming a hired gun is avoided through selecting appropriate methods for the 
task and data, avoiding cases that are beyond the practitioners' expertise, and requesting no background information on the case (e.g. P8: 'I don't want to know really anything at all'). With respect to this final strategy, previous research has demonstrated that having access to such information can make forensic experts vulnerable to errors (Dror et al. 2006). It should be noted, however, that for the linguistic expert the decision whether to use background information is largely dependent on the types of linguistic tasks. For example, in order to make accurate inferences about whether a particular phrase can be interpreted as a bribe, threat or warning, background (contextual) information would be required. Therefore, background information may be essential in some linguistic tasks, meaning that this finding could be different for practitioners outside of our sample.

Another common pattern with respect to professional duty was that most participants stressed the importance of limiting their evidence to that required by the brief and resisting the temptation to become the trier of fact, for example:

(14) one needs to be careful and to recognise that as a forensic linguist you're not (...) the judge and you're not the jury (P9)

(15) you have to be a friend of the court not the friend of one side or the other (P11)

(16) linguists should just present the data and allow the legal system to decide what its standard wants to be (P6)

One expert made a comment that suggests a connection between professional independence and the need for legal enculturation mentioned in 4.1 above:

(17) in the early days I probably made a few mistakes about [remaining independent] because I wasn't highly aware of how lawyers worked (P8)

A somewhat unexpected finding is to do with what seems to be a sense of social duty among the experts. It is clear they have an awareness of the social dimension of their work and the value of the contributions they make there, as is evident in the following two examples.

(18) well it means that I'm doing something that is erm socially valuable it contributes to the legal system and I hope to social justice' (P11)

(19) I think it is great that linguistics can help provide some information to prevent the justice system from just acting arbitrarily (P6)

Even an informant who construes their identity in matter-of-fact, detached terms does evoke the justice dimension:

(20) I consider myself to be a service provider erm yes basically that's the thing I am

(21) first of all I'm a service provider to law enforcement er to justice er and my job is to assist their work erm by doing forensic analysis with the help of linguistics (P4)

The sub-theme of duty of confidentiality, introduced by the interviewer (Questions 11 and 12 in Appendix II), has an unexpected twist to it in that, despite the informants' familiarity with the legal professional culture, they do not mention specific regulations to adhere to, or practical solutions to follow, in relation to the potentially sensitive material they handle. Rather, the practice of protecting data and not sharing findings other than with the relevant court actors and for case-related purposes is taken for granted and discussed in common-sense terms, as the example below shows. 
(22) it's not hard not to talk about things if you're not supposed to talk about them really is it? (P6)

\subsection{Knowledge and expertise}

It comes as no surprise that the interviewees draw on their knowledge of linguistics and its various methods but it is interesting to see discussions of the most appropriate methods for the case at hand, and their respective limitations. The experts mention the complexities inherent in forensic data and point out that modified or new methods have to be introduced ad casum. Some interviewees seem to echo one of Shuy's (2009) concerns about ethical issues in forensic linguistics, viz. how experts 'select from among the appropriate tools, theories, and research knowledge of linguistics that are relevant in a specific law case' (2009: 221). They also note the need for the academic community to engage in research for developing and validating impromptu methods prior to application:

(23) any erm linguistic question you look at what you are being asked, you look at the data and think about which are the most appropriate methods to use in that in that set of circumstances (P5)

(24) I think it is incumbent upon the academic community especially the universities to engage in research especially with more controversial areas in forensic linguistics such as authorship identification practices (...) to see what works and what doesn't (P6)

In addition to their own knowledge of linguistics and specialist expertise, the participants also refer to their knowledge of other people's abilities and expertise. For the experts, this knowledge is important in enabling them to reject or refer to colleagues the cases that are beyond their expertise. As a result, there are ethical implications also within this theme, specifically that experts should not take cases for which they do not have the requisite expertise.

(25) if it's not my field in linguistics or something I don't know about I don't do it (...) you shouldn't do it (P6)

(26) I recently had a request for example (...) and I said that was outside my expertise but I referred it to [name] because I know [name] works with that (P1)

Notably, and similar to the findings under the 'Customary practice and procedures' theme, the participants frequently refer to their knowledge and understanding of legal terms and the legal context, especially courtroom discourse. This legal knowledge is often presented as a necessary 'survival strategy'; by knowing what to expect, they can prepare for the worst, particularly in reference to cross-examination.

(27) I've been cross-examined in lots of cases and erm it's usually it's not that bad it's usually that they're trying to find a hole but I'm usually well aware of what they're trying to do and [and] I do know a lot about lawyer tactics so I know what they're trying to do (P11)

(28) I know in contract law they use the word 'puffing', which means it's okay to say things that are over-exaggerated because people understand it as such because you are just writing about your accomplishments (P6) 


\section{Conclusions}

The professional identity of the forensic linguistic expert witness is constructed by drawing on several resources, ones to do with customary practices and procedures, professional and social duty, and experts' knowledge and expertise. Cross-cutting these themes are various ethical considerations. Our informants do not speak of their work in terms of simply producing linguistic research which happens to be used in a legal or forensic context. On the contrary, their responses indicate a common experience of imparting linguistic knowledge in highly demanding institutional environments, an awareness of the need to protect themselves in the face of constraints and expectations which lead to difficult ethical choices, and an appreciation of the social value of expert witness work. While we concur in principle with Shuy (2002: 9) that 'the intersection of linguistics and law can be and is advantageously carried out separately and independently by both fields of expertise', what our findings do show is that the relationship between expert linguists and lawyers is much more intimate than has been given credit so far. Shuy (2002: 9) also suggests that forensic linguistics is unlike 'hyphenated' fields, such as psycholinguistics or sociolinguistics, which demand knowledge of two disciplines but, again, the findings indicate knowledge of the legal process is frequently referred to by the participants talking about their professional practice. According to Shuy (2002: 8), 'there is little reason for the data on which a linguist works to have the right to name that work' but we would argue that the totality of the expert linguist's working experience, including the nature of the data they work with, does warrant the designation of 'forensic linguistics'. In sum, we believe that far from being a convenient fiction, 'forensic linguist' is a shared identity with its unique set of praxeological, deontological and epistemic constituents.

At the same time, it is interesting to see how our informants talk about their experience. Perhaps the most striking finding here is that they often define their professional practice by what they do not, would not, and should not do as well as who they are not and should not be (see for example excerpts 14, 15 and 25, and section 4.2 above). They do not take cases that are beyond their expertise. They do not want extralinguistic information on the background of the case. They are not the judge and they are not the jury. They are no triers of facts and certainly should not become a hired gun. We believe this kind of apophatic discourse can have at least two explanations: the profession is still in statu nascendi, and/or it is an auxiliary, 'satellite' profession.

The first explanation may seem surprising at first glance. It is fifty years since Svartvik (1968) coined the term 'forensic linguistics' and the wider field's body of knowledge has been growing exponentially since the early 1990's. We know much more now than, say, ten years ago about authorship analysis, language competence assessment or semantic interpretation of disputed meanings. However, as it takes time for new knowledge to be disseminated, there is still a relatively poor awareness among law enforcement and the legal profession of what the field can offer, which, coupled with a lack of statutory regulation in many jurisdictions, means communication evidence still enjoys mixed fortunes when it comes to its social applicability and admissibility in court (see e.g. Chaski 2013 and Tiersma and Solan 2002).

The second explanation imposes itself because it is auxiliary professions that are often defined by negation. For example, paralegals can draft contracts but not sign them, and paramedics can help save lives but do not, would not, and should not administer most prescription drugs or perform most medical procedures. Curiously, while a paramedic can graduate to becoming a doctor through further training, for a linguist choosing to act as an expert witness the progression is in the opposite direction, i.e. from an independent, fully fledged to an ancillary role and our findings suggest this identity shift is a complex one, mostly because the job of the forensic linguist is contingent on the needs of law enforcement and legal practice, and circumscribed by the rules of the relevant institutions. 
It is of course also possible to treat the use of negation as suggestive of there being the 'right' way of doing things, whereby it could be perceived as a legitimisation strategy, similar to what Bucholtz and Hall (2005: 601) call 'authentication'. The informants' implicit construction of the various alternative positions as not professional (or unprofessional) can be reasonably assumed to constitute an attempt at distancing themselves from unprofessional practice, and hence legitimising their professional identity. For example, in excerpts 14 and 15 above, negation is used as a resource to introduce the unprofessional identity and simultaneously reinforce the professional role.

Because it is uncertain to what extent our findings are generalizable, a larger-scale study using a jurisdictionally varied sample of practitioners representing a wide range of linguistic specialisms would certainly be a natural next step for further research. Our methodological orientation has also meant a focus on shared experience, which is why we did not pursue in any depth codes only appearing sporadically (for example, one participant discussed the difficulties of remaining confidential when the media becomes involved, and two emphasised the importance of contributing to the field through writing textbooks and making sure there are translations to develop the field internationally). These incidental codes, however, could well prove to be identity-building if, again, a larger sample of informants were used. Similarly, while efforts were made to be inclusive of the various specialisations within forensic linguist expert witness work, the range of linguistic tasks that they do can in fact be circumscribed by the jurisdiction in which the practitioner works. Future research might therefore seek to understand to what extent the practitioners' professional identity is shaped by the needs (and corresponding laws) of different jurisdictions. A meta-analysis of existing first-hand accounts of experts' involvement in investigative work and/or law cases could yield interesting results here. Finally, our informants have all been making significant contributions to the wider forensic linguistic scholarship and are very well conversant with the academic side of the discipline as well as expert witness work. It would thus be interesting to see how identity construction worked with those just entering the field, with the relevant frames of reference already in place for them to rely on. Do younger and/or less experienced colleagues still identify themselves by negation? Do those graduating from the still relatively new degree programmes in forensic linguistics who go on to work in law enforcement settings have a markedly different sense of identity? How do novice experts become socialized within the occupation? How do they perform their role as expert witness? Similar research has been conducted within the area of occupational socialization ${ }^{3}$ with other professions, such as the police (Chen, 2016), lawyers (Mertz, 2007), and social workers (Wiles, 2013). There is clearly work still to be done and we hope this article can serve as a useful point of departure.

\section{Acknowledgements}

We are deeply indebted to our informants, without whom this project would not have been possible. Their time, patience and data input are greatly appreciated.

\section{Notes}

1 But note there are of course regulations governing the production, use and admissibility of expert evidence as such. In the UK, for example, Part 33 of The Criminal Procedure Rules is devoted specifically to expert evidence and stipulates the expert's opinion must be '(a) objective and unbiased, and (b) within the expert's area or areas of expertise' (CPR 2014, 32.2). In Germany, the work of forensic linguists based in law enforcement laboratories has been accredited under the EU standard ISO 17020 (see Ehrhardt 2012), although those who work 
independently are not required to apply the standard. Depending on the jurisdiction in the US, Daubert (1993) and/or Frye (1923) can govern the admissibility of expert evidence (see Solan and Tiersma (2005) for a discussion of how different types of linguistic evidence stand up to the Daubert standards).

The interviewer was one of the authors (Clarke), who was a student on Aston University's Master's programme in Forensic Linguistics at the time, and it is important to note the effect her student status may have had on the interviewees. On the one hand, they might have assumed the interviewer to be a novice and thus taken more care in explaining particular concepts in an attempt to educate her. On the other hand, the interviewees might have noted her status as specifically a forensic linguistics student and assumed shared knowledge. Identity building, nonetheless, occurs in many types of talk, with a variety of dynamic interactant roles and expectations at play as the conversation progresses and information is exchanged. We do not believe any potential observer paradox effects have impacted on our findings in any significant way also because of the dominant interaction roles assumed, viz. interviewee and interviewer.

Occupational socialisation refers to "the process by which one generation passes on to another the technical knowledge, ideologies, and expected behaviour deemed necessary to perform an occupational role" (Trice 1993: 114).

\section{References}

Ainsworth, J. (2010) A Lawyer's Perspective: Ethical, Technical, and Practical Considerations in the Use of Linguistic Expert Witnesses. The International Journal of Speech Language and the Law 16(2): 279--291.

Angouri, J. and Marra, M. (2011) 'OK one last thing for today then': Constructing Identities in Corporate Meeting Talk” In M. Marra and J. Angouri (eds). Constructing Identities at Work 85--100. New York: Palgrave Macmillan.

Anthony, L. (2016) AntConc (Version 3.4.4) [Computer software]. Tokyo, Japan: Waseda University. Retrieved on 27 March 2016 from http://www.laurenceanthony.net.

Baker, P. (2006) Using Corpora in Discourse Analysis. London: Continuum.

Baker, P., Gabrielatos, C., KhosraviNik, M., Krzyżanowski, M., McEnery, T. and Wodak, R. (2008) A Useful Methodological Synergy? Combining Critical Discourse Analysis and Corpus Linguistics to Examine Discourses of Refugees and Asylum Seekers in the UK Press. Discourse and Society 19(3): 273--306.

Bell, A. (1984) Language style as audience design. Language in Society 13(02): 145--204.

Biber, D. (2006) Stance in Spoken and Written University Registers. Journal of English for Academic Purposes 5: 97--116.

Biber, D., Johansson, S., Leech, G., Conrad, S. and Finegan, E. (1999) The Longman Grammar of Spoken and Written English. London: Longman.

Boswood, T. (1999) Redefining the Professional in International Professional Communication. In R. L. Carl and G. Dixie (eds) Exploring the Rhetoric of International Professional Communication: An Agenda for Teachers and Researchers 110--128. New York: Baywood Press. 
Bouchard, R. (1998) Art Therapy and Its Shadow: A Jungian Perspective on Professional Identity and Community. Art Therapy: Journal of the American Art Therapy Association 15: $158--164$.

Braun, V. and Clarke, V. (2006) Using Thematic Analysis in Psychology. Qualitative Research in Psychology 3(2): 77--191.

Brubaker, R. and Cooper, F. (2000) Beyond 'Identity'. Theory and Society 29: 1--47.

Bucholtz, M. and Hall, K. (2005) Identity and Interaction: A Sociocultural Linguistic Approach. Discourse Studies 7(4-5): 585--614.

Bunn, S. and Foxen, S. (2015) Forensic Language Analysis. POST Note Number 509, Parliamentary Office of Science and Technology

Butters, R. R. (2009) The Forensic Linguist's Professional Credentials. The International Journal of Speech, Language and the Law 16(2): 237--252.

Butters, R. R. (2012) Retiring President's Closing Address: Ethics, Best Practices, and Standards. In Proceedings of the International Association of Forensic Linguists' Tenth Biennial Conference. Birmingham: Centre for Forensic Linguistics.

Chaemsaithong, K (2011) In Pursuit of an Expert Identity: A Case Study of Experts in the Historical Courtroom. International Journal for the Semiotics of Law 24(4): 471--490.

Chaemsaithong, K. (2012) Performing Self on the Witness Stand: Stance and Relational Work in Expert Witness Testimony. Discourse and Society 23(5): 465--486.

Chaski, C. (2013) Best practices and admissibility of forensic author identification. Journal of Law and Policy 21(2): 333--376.

Chen, Z. (2016) Measuring Police Subcultural Perceptions: A study of frontline police officers in China. Singapore: Springer.

Coulthard, M. (1997) A Failed Appeal. International Journal of Speech, Language and the Law 4(2): 281--302.

Coulthard, M. (1998) Making Texts Speak: The Work of the Forensic Linguist. Studia Anglica Posnaniensia: International review of English Studies: 117--130.

Coulthard, M. (2005) The Linguist as Expert Witness. Linguistics and the Human Sciences 1(1): 39--58.

Coulthard, M. (2010) Experts and Opinions: In My Opinion. In M. Coulthard and A. Johnson (eds) The Routledge Handbook of Forensic Linguistics 473--486. Abingdon: Routledge.

Coulthard, M. Johnson, A., Kredens, K. and Woolls, D. (2010) Plagiarism: Four Forensic Linguists' Responses to Suspected Plagiarism. In M. Coulthard and A. Johnson (eds) The Routledge Handbook of Forensic Linguistics. Abingdon: Routledge.

Dror, I. E., Charlton, D., and Péron, A. E. (2006) Contextual Information Renders Experts Vulnerable to Making Erroneous Identifications. Forensic Science International 156(1): 74-78 . 
Durant, A. (1996) On the Interpretation of Allusions and Other Innuendo Meanings in Libel Actions: The Value of Semantic and Pragmatic Evidence. Forensic Linguistics 3(2): 195-210.

Dvir, N. and Avissar, I. (2013) Constructing a Critical Professional Identity Among Teacher Candidates During Service-Learning. Professional Development in Education 40(3): 398-415.

Dyer, J. and Keller-Cohen, D. (2000) The Discursive Construction of Professional Self through Narratives of Personal Experience. Discourse Studies 2(3): 283--304.

Ehrhardt, S. (2012) Forensic Linguistics accredited: Four years of experiences with ISO 17020 in authorship analysis. Proceedings of the International Association of Forensic Linguists Conference (Porto, 2012). Retrieved on 18 January 2018 from < http://ler.letras.up.pt/uploads/ficheiros/13618.pdf>

Feen-Calligan, H. R. (2005) Constructing Professional Identity in Art Therapy through Service-Learning and Practica. Art Therapy: Journal of the American Art Therapy Association 22(3): 122--131.

Finegan, E. (2009). Expert Linguists and the Whole Truth. The International Journal of Speech, Language and the Law 16(2): 267--277.

Foucault, M. (1972). The Archeology of Knowledge (trans. Alan Sheridan). London: Tavistock.

Gibbons, J. (2011) Towards a framework for communication evidence. International Journal of Speech, Language and the Law 18(2): 233--260.

Grant, T. (2013) TXT 4n6: Method, Consistency and Distinctiveness in the Analysis of SMS Text Messages. Journal of Law and Policy 21(2): 467--494.

Grant, T. (2017) Duppying Yoots in a Dog Eat Dog World, kmt: Determining the Senses of Slang Terms for the Courts. Semiotica 216: 479--495.

Heffer, C. (2005) The Language of Jury Trial: A Corpus-Aided Analysis of Legal-Lay Discourse. Basingstoke: Palgrave Macmillan.

IAFL (2013) International Association of Forensic Linguists Code of Practice. Retrieved on 18 January 2018 from <http://www.iafl.org/uploads/IAFL_Code_of_Practice_1.pdf > .

Ibarra, H. (1999) Provisional Selves: Experimenting with Image and Identity in Professional Adaptation. Adm. Sci. Q. 44(4): 764--791.

Jaworska, S. (2016) A Comparative Corpus-Assisted Discourse Study of the Representations of Hosts in Promotional Tourism Discourse. Corpora 11(1): 83--111.

Johnson, A. and Coulthard, M. (2010) Introduction: Current Debates in Forensic Linguistics. In M. Coulthard and A. Johnson (eds) The Routledge Handbook of Forensic Linguistics 1-16. Abingdon: Routledge.

Koller, V. (2011) 'Hard-Working, Team-Oriented Individuals': Constructing Professional Identities in Corporate Mission Statements. In M. Marra and J. Angouri (eds) Constructing Identities at Work 103--126. New York: Palgrave Macmillan. 
Lagorgette, D. (2011) Pragmatics in the Courtroom: Violent Speech Acts, Law, and the Linguist in France. Pragmatics and Society 2(2): 187--204.

Lave, J. and Wenger, E. (1991) Situated Learning: Legitimate Peripheral Participation. New York: Cambridge University Press.

Li, C. and Ran, Y. (2016) Self-Professional Identity Construction through Other-Identity Deconstruction in Chinese Televised Debating Discourse. Journal of Pragmatics 94: 47-63.

Lubet, S. (1998-1999) Expert Witnesses: Ethics and Professionalism. Georgetown Journal of Legal Ethics 12: 465--488.

Marra, M. and Angouri, J. (2011) Investigating the Negotiation of Identity: A View from the Field of Workplace Discourse. In M. Marra and J. Angouri (eds) Constructing Identities at Work 1--16. New York: Palgrave Macmillan.

Mertz, E. (2007) The Language of Law School: Learning to "Think Like a Lawyer”. New York: Oxford University Press.

Morris, P. W. G., Patel, M. B. and Wearne, S. H. (2000) Research into Revising the APM Project Management Body of Knowledge. International Journal of Project Management 18: $155--164$.

Nunberg, G. (2009). Is it ever okay not to disclose work for hire? The International Journal of Speech, Language and the Law 16(2): 227--235.

Olsson, J. (2008). Forensic Linguistics. $2^{\text {nd }}$ ed. London and New York: Continuum.

Olsson, J. (2012). Wordcrime: Solving crime through forensic linguistics. London and New York: Continuum.

Orpin, D. (2014) Discussing Science in the Public Sphere: A Corpus-Assisted Study of WebBased Interaction Concerning the Measles, Mumps and Rubella (MMR) Triple Vaccine. $\mathrm{PhD}$ Thesis (Unpublished). Birmingham: University of Birmingham.

Parker, I. (2015) Critical Discursive Psychology. $2^{\text {nd }}$ ed. Basingstoke: Palgrave Macmillan.

Partington, A. (2006) The Linguistics of Laughter: A Corpus-Assisted Study of Laughter-Talk. Abingdon: Routledge.

Partington, A., Duguid, A. and Taylor, C. (2013) Patterns and Meaning in Discourse: Theory and Practice in Corpus-Assisted Discourse Studies (CADS). Amsterdam: John Benjamins Publishing.

Polkinghorne, D. (1988) Narrative Knowing and the Human Sciences. Albany: State University of New York Press.

Pratt, M. G., Rockmann, K. W. and Kaufmann, J. B. (2006) Constructing Professional Identity: The Role of Work and Identity Learning Cycles in the Customization of Identity among Medical Residents. Academy of Management Journal 49 (2): 235--262.

Rieber, R.W. and Stewart, W. A. (1990) The Interactions of the Language Sciences and the Law: An Introduction to the Contributions. In R.W. Rieber and W. A. Stewart (eds) The 
Language Scientist as Expert in the Legal Setting: Issues in Forensic Linguistics 1--4. USA: The New York Academy of Sciences.

Sacks, M. J. (1990) Expert Witnesses, Nonexpert Witnesses, and Nonwitness Experts. Law and Human Behavior 14(4): 291--313.

Schröter, M. and Storjohann, P. (2015) Patterns of Discourse Semantics: A Corpus-Assisted Study of Financial Crisis in British Newspaper Discourse in 2009. Pragmatics and Society 6(1): 43--66.

Shuy, R. W. (1993) Language Crimes: The Use and Abuse of Language Evidence in the Courtroom. Cambridge, MA: Blackwell Publishers.

Shuy, R. W. (2000) Breaking into Language and Law: The Trials of the Insider-Linguist. In J. E. Alatis, H. E. Hamilton and A. Tan (eds) Linguistics, Language, and the Professions: Education, Journalism, Law, Medicine, and Technology. Georgetown University Round Table on Languages and Linguistics 2000 67--80. Washington: Georgetown University Press.

Shuy, R. W. (2002) Linguistic Battles in Trademark Disputes. New York: Palgrave Macmillan.

Shuy, R. W. (2006) Linguistics in the Courtroom: A Practical Guide. Oxford: Oxford University Press.

Shuy, R. W. (2008) Fighting Over Words: Language and Civil Law Cases. Oxford: Oxford University Press.

Shuy, R. W. (2009) Ethical Questions in Forensic Linguistics: Introduction to Papers from a Linguistic Society of America Panel Presentation, San Francisco, California, 9 January 2009. The International Journal of Speech, Language and the Law 16(2): 219--226.

Spencer-Oatey, H. (2007) Theories of Identity and the Analysis of Face. Journal of Pragmatics 39(4): 639--656.

Sullivan, W. M. (2000) Medicine under Threat: Professionalism and Professional Identity. CMAJ 162 (5): 673--675.

Taylor, C. (2013) Searching for Similarity Using Corpus-Assisted Discourse Studies. Corpora 8(1): 81--113.

Solan, L. M. and Tiersma, P. M. (2005) Speaking of Crime: The Language of Criminal Justice. Chicago: University of Chicago Press.

Solan, L. M. and Tiersma, P. M. (2004) Author Identification in American Courts. Applied Linguistics 25(4): 448--465.

Tiersma, P. and Solan, L. M. (2002) The Linguist on the Witness Stand: Forensic Linguistics in American Courts, Language 78(2): 221--239.

Tkačuková, T. (2015) A Corpus-Assisted Study of the Discourse Marker well as an Indicator of Judges' Institutional Roles in Court Cases with Litigants in Person. Corpora 10(2): 145-170 . 
Tognini-Bonelli, E. (2001). Corpus linguistics at work. Amsterdam/Philadelphia: John Benjamins Publishing.

Tracy, K. (2009) How Questioning Constructs Appellate Judge Identities: The Case of a Hearing about Same-Sex Marriage. Discourse Studies 11: 199--221.

Tracy, K. (2011) Identity-Work in Appellate Oral Argument: Ideological Identities within a Professional One. In M. Marra and J. Angouri (eds) Constructing Identities at Work 175-199. New York: Palgrave Macmillan.

Trice, H. M. (1993) Occupational subcultures in the workplace. Ithaca, New York: ILR Press

van Dijk T. A. (2000) Ideology and Discourse. A Multidisciplinary Introduction. English Version of an Internet Course for the Universitat Oberta de Catalunya (UOC). London: Sage.

Verling, R. (2014) Exploring the Professional Identity of Counselling Psychologists: A Mixed Methods Study. (Unpublished $\mathrm{PhD}$ dissertation). Wolverhampton: University of Wolverhampton.

Wadeson, H. (1977) The Identity of the Art Therapist: Professional Self-Concept and Public Image. In R. H. Shoemaker and S. Gonick-Barris (eds) Creativity and the Art Therapist's identity: Proceedings of the $7^{\text {th }}$ Annual American Art Therapy Association Conference 38-42. Baltimore: American Art Therapy Association.

Watson, C. (2006) Narratives of Practice and the Construction of Identity in Teaching. Teachers and Teaching 12(5): 509--526.

Wiles, F. (2013) 'Not easily put into a box': Constructing Professional Identity. Social Work Education 32(7): 854--866.

Zhang, M. and Mihelj, S. (2012) Hong Kong Identity and the Press-Politics Dynamics: A Corpus-Assisted Discourse Study. Asian Journal of Communication 22(5): 506--527.

\section{Cases/laws cited}

Criminal Procedure Rules, UK Ministry of Justice, available at https://www.justice.gov.uk/courts/procedure-rules/criminal

Daubert v. Merrell Dow Pharmaceuticals, Inc., 509 U.S. 579 (1993).

Frye v. United States, 293 F. 213 (D.C. Cir. 1923).

DIN EN ISO/IEC 17020:2012, (2012). Conformity Assessment - Requirements for the operation of various types of bodies performing inspection (ISO/IEC 17020:2012); German and English version EN ISO/IEC 17020:2012.

\section{Appendix I}


Stance markers used in the analysis (adapted from Biber 2006)

Modal and semi-modal verbs

possibility / permission / ability: can, could, may, might

necessity / obligation: must, should, ought to, have to

prediction / volition: will, would, be going to

Verbs

certainty: know

likelihood: believe, think

attitude: hope

Adjectives (+ that-clause)

clear

possible

sure

certain

Adverbs

certainty: actually, certainly, in fact

likelihood: apparently, perhaps, possibly, likely

attitude: amazingly, importantly, surprisingly

style/perspective: generally, typically

\section{Appendix II}

Questions asked of the informants

1. Can you tell me how you got involved in practising forensic linguistics?

2. How often do you do case work? And who approaches you to assist in case work?

3. What sort of cases do you prefer to work on?

4. What do you consider to be your duty as an expert witness?

5. What do you do to make sure your analyses are accurate and reliable? 
6. What measures do you take to remain unbiased?

7. How do you decide which method(s) to use?

8. What is your opinion about giving an opinion in your report? And have you ever been asked to withhold your opinion?

9. In your specialist area and the field in general, what do you understand to be the limits of forensic linguistic analysis?

10. Your reports and testimonies are directed to the trier of fact, how do you manage the technical communication to lay people?

11. Can you describe situations where it is difficult to remain confidential?

12. What measures do you take to remain confidential?

13. Do you ever avoid assignments? And for what reasons?

14. Have you ever begun a case and stopped? If so why?

15. Have you ever been cross examined? If so, can you tell me about your experience of cross-examination?

16. What does it mean to be a linguist expert witness?

17. How do you feel when you work on a case?

18. What are your main motivations for being an expert witness?

19. How do you feel about the International Association of forensic linguists?

20. What do you think the future holds for expert witnesses especially in relation to [your specialist field]?

21. What is the future for forensic linguistics?

22. What are your plans? 